\title{
Hexahedral modular bioreactor for solid state bioprocesses
}

\author{
Daniele Colembergue da Cunha $\cdot$ Jeferson Avila Souza \\ Luiz Alberto Oliveira Rocha · Jorge Alberto Vieira Costa
}

Received: 9 December 2008/ Accepted: 9 July 2009/Published online: 24 July 2009

(C) Springer Science+Business Media B.V. 2009

\begin{abstract}
The design of a modular bioreactor for solid state fermentation is a promising development because it keeps the homogeneity of the bed at optimal levels. This study determines the optimum geometry of elementary modules of hexahedral bioreactors subjected to constant volume. The bioreactors have a square section and do not need an external cooling system, because the optimization limits the temperature of the bed to $35^{\circ} \mathrm{C}$. The geometric optimization followed the Constructal principle of minimum heat resistance. The numerical simulations take into account the following parameters: inlet air temperature and velocity, and module volume. Once the elementary module has been selected, the total volume of the bioreactor can be calculated.
\end{abstract}

Keywords Elementary module - Constructal ·

Hexahedral bioreactor · Numerical simulation

\section{List of symbols}

$C_{\mathrm{p}} \quad$ specific heat $\left(\mathrm{J} \mathrm{kg}^{-1}{ }^{\circ} \mathrm{C}^{-1}\right)$

$(D / L)$ ratio of width and length of the modules, dimensionless

$f \quad$ air capacity to absorb water ( $\mathrm{kg}$ water, $\mathrm{kg}$ air) ${ }^{\circ} \mathrm{C}^{-1}$

$K \quad$ permeability $\left(\mathrm{m}^{2}\right)$

$k$ thermal conductivity $\left(\mathrm{w} \mathrm{m}^{-1}{ }^{\circ} \mathrm{C}^{-1}\right)$

D. C. da Cunha $\cdot$ J. A. V. Costa $(\bowtie)$

School of Chemical and Food Engineering, Federal University of Rio Grande, Rio Grande, RS, Brazil

e-mail: jorge@pq.cnpq.br

J. A. Souza · L. A. O. Rocha

School of Engineering, Federal University of Rio Grande, Rio

Grande, RS, Brazil $m \quad$ coefficient of cell maintenance, $\mathrm{kg}$ substrate $\left(\mathrm{kg}^{-1}\right.$ biomass) $\mathrm{s}^{-1}$

$p \quad$ pressure $(\mathrm{Pa})$

$R_{\mathrm{CO}_{2}}$ rate of $\mathrm{CO}_{2}$ formation, $\mathrm{g}$ (100 g cultivation media) ${ }^{-1} \mathrm{~s}^{-1}$

$R_{\mathrm{S}} \quad$ rate of substrate consumption, $\mathrm{g}$ (100 $\mathrm{g}$ cultivation media) ${ }^{-1} \mathrm{~s}^{-1}$

$R_{\mathrm{x}} \quad$ rate of microorganism growth, $\mathrm{g}$ (100 $\mathrm{g}$ cultivation media) ${ }^{-1} \mathrm{~s}^{-1}$

$S \quad$ term energy source $\left(\mathrm{W} \mathrm{m}^{-3}\right)$

$t \quad$ time (s)

$T$ temperature $\left({ }^{\circ} \mathrm{C}\right)$

$\vec{v} \quad$ velocity $\left(\mathrm{m} \mathrm{s}^{-1}\right)$

$V \quad$ volume, 1

$\left[\mathrm{CO}_{2}\right]$ concentration of $\mathrm{CO}_{2}, \mathrm{~g} \quad(100 \mathrm{~g}$ cultivation media) ${ }^{-1}$

[S] concentration of substrate, $\mathrm{g}$ (100 $\mathrm{g}$ cultivation media) $^{-1}$

$[X]$ concentration of microorganism, $\mathrm{g}$ (100 $\mathrm{g}$ culti-

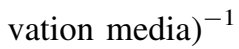

$Y_{\mathrm{CO}_{2}} \quad$ yield of substrate- $\mathrm{CO}_{2}, \mathrm{~kg} \mathrm{CO} \mathrm{CO}_{2}(\mathrm{~kg} \text { substrate })^{-1}$

$Y_{\mathrm{X} / \mathrm{S}}$ yield of substrate-biomass, $\mathrm{kg}$ biomass $(\mathrm{kg}$ substrate $)^{-1}$

\section{Greek letters}

$\varepsilon \quad$ porosity of the bed, dimensionless

$\Delta H \quad$ heat of reaction $\left(\mathrm{J} \mathrm{kg}^{-1}\right)$

$\mu \quad$ absolute viscosity (Pa s)

$\mu_{\max } \quad$ specific maximum velocity of growth $\left(\mathrm{s}^{-1}\right)$

$\lambda$ enthalpy of vaporization, $\mathrm{J}(\mathrm{kg} \text { water })^{-1}$

$\rho \quad$ density $\left(\mathrm{kg} \mathrm{m}^{-3}\right)$

$\overline{\bar{\tau}} \quad$ stress tensor $\left(\mathrm{kg} \mathrm{m}^{-1} \mathrm{~s}^{-2}\right)$

\section{Subscripts}

ef effective

in admission of air 


$\begin{array}{ll}\text { opt } & \text { optimal } \\ \text { out } & \text { exit of air } \\ \mathrm{S} & \text { solid } \\ \mathrm{Ss} & \text { dry solid } \\ x, y, z & \text { directions of vector velocity }\end{array}$

\section{Introduction}

Solid state bioprocesses (SSB) involve the culture of microorganisms on moist solid substrates with no free water in the inter-particle spaces and with a continuous gas phase (Dalsenter et al. 2005; Mitchell and von Meien 2000; Raghavarao et al. 2003; Rahardjo et al. 2006). These processes can be used in the production of enzymes, pesticides, food stuffs, animal feed, among others (Smits et al. 1999; Soccol and Vandenberghe 2003). SSB have numerous advantages over submersed bioprocesses, such as low cost and high productivity (Couto and Sanromán 2006).

Despite its potential, few SSB that are studied in laboratories actually make the transition to full-scale production. This is because it is difficult to control the key variables (temperature and water activity) under optimal conditions for the growth and formation of the product in large bioreactors (Dalsenter et al. 2005). It is also difficult to keep these variables homogeneous in the bioreactor (Fernández-Fernández and Pérez-Correa 2007).

The modularity concept offers new perspectives on how to efficiently manage product development. It is a classical methodology of splitting a complex system into small portions (or subsystems), in order to simplify the operation and management. Subsystems that are sensitive to the conditions of supply and demand are good candidates to form a module because they enable rapid adaptation to product changes (Leung et al. 2005). A bioreactor subdivided into smaller suitable geometric modules could facilitate the control of the key variables of the bioprocess inside the bioreactor. Furthermore, through the geometric optimization of the modules it is possible to maintain the bed temperature below a certain limit, without cooling equipment. The possibility of using less equipment shows how geometric optimization can be used as a tool for the ecologically correct management of energy. The proposal of geometric optimization is based upon the Constructal principle of minimum heat resistance, under constant volume restriction (Bejan and Lorente 2004). The hexahedral shape of the modules, a novelty in bioreactors, has the extra advantage of facilitating the assembling and storing of the set of modules.

This study proposes a modular hexahedral reactor for SSB, with optimized geometry for different operational conditions. The optimized geometry allows the bioreactor to operate without the need for an external cooling system. The admission of air provides oxygen and cooling to the system. In order to reduce the time and cost of the project of new equipment, numerical simulation was utilized (Maliska 2004) through a computer package to solve a mathematical model that represents the bioprocess.

\section{Materials and methods}

The proposed bioreactor works in bioprocesses that cultivate Aspergillus niger fungi in a substrate of a mixture of rice meal $(85 \%)$ and husk $(15 \%)$, under $50 \%$ moisture and an initial inoculum concentration $\left[X_{0}\right]$ of $4 \times 10^{8}$ spores (100 $\mathrm{g}$ of cultivation media $)^{-1}$, in accordance with previously described cultivations (Hasan et al. 1998; Martins et al. 2006). The thermal properties of the solid are: thermal conductivity $(k) 0.4139 \mathrm{~W} \mathrm{~m}^{-1}{ }^{\circ} \mathrm{C}^{-1}$ and specific heat $\left(C_{\mathrm{p}}\right)$ of $2,500 \mathrm{~J} \mathrm{~kg}^{-1}{ }^{\circ} \mathrm{C}^{-1}$. The bed, through which saturated air flows, is characterized by permeability $(K)$ equal to $10^{-8} \mathrm{~m}^{2}$.

\section{Mathematical model}

The bioprocess was represented by a mathematical model which considers the conservation of mass, momentum and energy equations, shown in Eqs. 1-3.

$\frac{\partial \rho}{\partial t}+\nabla \cdot(\rho \vec{v})=0$

where $\rho$ is the density of the air, $t$ is time $e \vec{v}$ is its velocity through the bed.

$\frac{\partial(\rho \vec{v})}{\partial t}+\nabla \cdot(\rho \vec{v} \vec{v})=-\nabla p+\nabla \cdot(\overline{\bar{\tau}})-\frac{\mu}{K} \vec{v}$

$p$ is pressure, $\overline{\bar{\tau}}$, the stress tensor and $(\mu \vec{v} / K)$, the term of force, which represents the difficulty of flowing of the fluid imposed by the porous medium ( $\mu$ is the absolute viscosity of the fluid).

$$
\begin{aligned}
& \frac{\partial\left(\varepsilon \rho C_{\mathrm{pf}} T+(1-\varepsilon) \rho_{\mathrm{s}} C_{\mathrm{ps}} T\right)}{\partial t}+\nabla \cdot\left[\left(\vec{v}\left(\rho C_{\mathrm{pf}} T+p\right)\right]\right. \\
& \quad=k_{\mathrm{ef}} \nabla^{2} T+S
\end{aligned}
$$

where the subscripts $\mathrm{f}$ and $\mathrm{s}$ of the terms $C_{\mathrm{p}}$ refer to the fluid and solid, respectively, $T$ is the temperature, $k_{\mathrm{ef}}$ is the weighted mean between the thermal conductivity of the solid and of the air, and $S$ is the term of the energy source due to the heat generated by the metabolic activities of the microorganism.

In this mathematical model, the density $(\rho)$ and moisture of the bed were assumed to be constant, as in previously published work (Ashley et al. 1999; Mitchell et al. 1999; Mitchell and von Meien 2000; Sangsurasak and Mitchell 
1995a, b; Sangsurasak and Mitchell 1998). The evaporation of the bed was considered negligible, since this hypothesis was experimentally confirmed in work of Hasan et al. (1998), in which the velocity of the incoming air $\left(v_{\text {in }}\right)$ and temperature gradients were used in a similar fashion as they were in this work. However, both the removal of heat by convection and evaporation were taken into consideration in the conservation of energy equation (second term on the left side of Eq. 3). For this reason, the factor $\lambda \mathrm{f}$ was added to the term $C_{\mathrm{pf}}$, where $\mathrm{f}$ is the ability of air to absorb water and $\lambda$ is the enthalpy of vaporization. This factor considers that the air remains saturated while flowing through the bed: the evaporation of water to maintain saturation gives the air more effective specific heat (Mitchell et al. 2003).

In Eq. 3, the heat generation is directly proportional to $\mathrm{CO}_{2}$ formation and is defined in Eq. 4.

$S=(1-\varepsilon) \rho_{\mathrm{ss}}(-\Delta H) R_{\mathrm{CO}_{2}}$

where $\varepsilon$ is the porosity of bed, $\rho_{\mathrm{ss}}$ is the density of dry solid, $(-\Delta H)$, the formation heat of $\mathrm{CO}_{2}$ and $R_{\mathrm{CO}_{2}}$, the rate of $\mathrm{CO}_{2}$ formation. $R_{\mathrm{CO}_{2}}$ is defined as:

$R_{\mathrm{CO}_{2}}=\frac{\mathrm{d}\left[\mathrm{CO}_{2}\right]}{\mathrm{d} t}=Y_{\mathrm{CO}_{2}} R_{\mathrm{s}}$

where $Y_{\mathrm{CO}_{2}}$ is the yield of substrate- $\mathrm{CO}_{2}$ and $R_{\mathrm{s}}$, the rate of substrate consumption.

$R_{\mathrm{S}}$ is calculated through (Lareo et al. 2006; SaucedoCastañeda et al. 1990):

$R_{\mathrm{S}}=-\frac{\mathrm{d}[S]}{\mathrm{d} t}=\frac{1}{Y_{\mathrm{X} / \mathrm{S}}} R_{\mathrm{X}}+m[X]$

where $Y_{\mathrm{X} / \mathrm{S}}$ is the yield of substrate-biomass, $R_{\mathrm{x}}$ is the rate of microorganism growth, $m$ is the cell maintenance coefficient and $[X]$ is the cell concentration.

$R_{\mathrm{x}}$ follows the logistic kinetic profile (Lareo et al. 2006; Mitchell et al. 2004a; Saucedo-Castañeda et al. 1990):

$R_{\mathrm{x}}=\frac{\mathrm{d}[X]}{\mathrm{d} t}=\mu_{\max }[X]\left(1-\frac{[X]}{[X]_{\max }}\right) \quad$ at $t=0,[X]=\left[X_{0}\right]$

where $\mu_{\max }$, the maximum specific velocity growth and $[X]_{\max }$, the maximum cell concentration. These variables were experimentally confirmed for the Aspergillus niger in moist cassava meal (Saucedo-Castañeda et al. 1990), according to Eqs. 8 and 9, respectively.

$$
\begin{aligned}
\mu_{\max }= & \frac{2.694 \times 10^{11} e^{\{-70225 /[8.314(T+273)]\}}}{1+1.3 \times 10^{47} e^{\{-283356 /[8.314(T+273)]\}}} \\
{[X]_{\max }=} & 0.0000473 T^{4}-0.00403 T^{3}-0.016 T^{2}+7.95 T \\
& -127.08
\end{aligned}
$$

Computer simulation and geometric optimization

The mathematical model previously presented was applied in a bioreactor made up of hexahedral modules with insulated walls and front and rear openings, through which the air flows, as shown in Fig. 1. The linking of the elementary modules, corresponding to the desired output, will make up the modular reactor.

The boundary and initial conditions for the computer domain shown in Fig. 1 are:

$$
\begin{gathered}
\text { in } x=0,0<y<D, 0<z<D \text { and } t>0 \\
T=T_{\text {in }}, v_{\mathrm{x}}=v_{\text {in }}, v_{\mathrm{y}}=0, v_{\mathrm{z}}=0 \\
x=L, 0<y<D, 0<z<D \text { and } t>0 \\
\frac{\partial T}{\partial x}=0, \frac{\partial v_{\mathrm{x}}}{\partial x}=0, v_{\mathrm{y}}=v_{\mathrm{z}}=0
\end{gathered}
$$

$y=D$ and $y=0,0 \leq x \leq L, 0 \leq z \leq D$ and $t>0$

$$
\frac{\partial T}{\partial y}=0, \frac{\partial v_{\mathrm{y}}}{\partial y}=0, v_{\mathrm{x}}=v_{\mathrm{z}}=0
$$

$z=D$ and $z=0,0 \leq x \leq L, 0 \leq z \leq D$ and $t>0$

$$
\frac{\partial T}{\partial z}=0, \frac{\partial v_{\mathrm{z}}}{\partial z}=0, v_{\mathrm{x}}=v_{\mathrm{y}}=0
$$

$$
\text { at } \begin{aligned}
t & =0,0<x<L, 0<y<D, 0<z<D \\
T & =T_{\text {in, }} v_{\mathrm{x}}=v_{\mathrm{y}}=v_{\mathrm{z}}=0,[X]=\left[X_{0}\right],\left[\mathrm{CO}_{2}\right]=0,[S] \\
& =\left[S_{0}\right]
\end{aligned}
$$

A computer program, Gambit (see 2.3.16, ANSYS, Inc., US), was utilized for discretization of the domain and grid

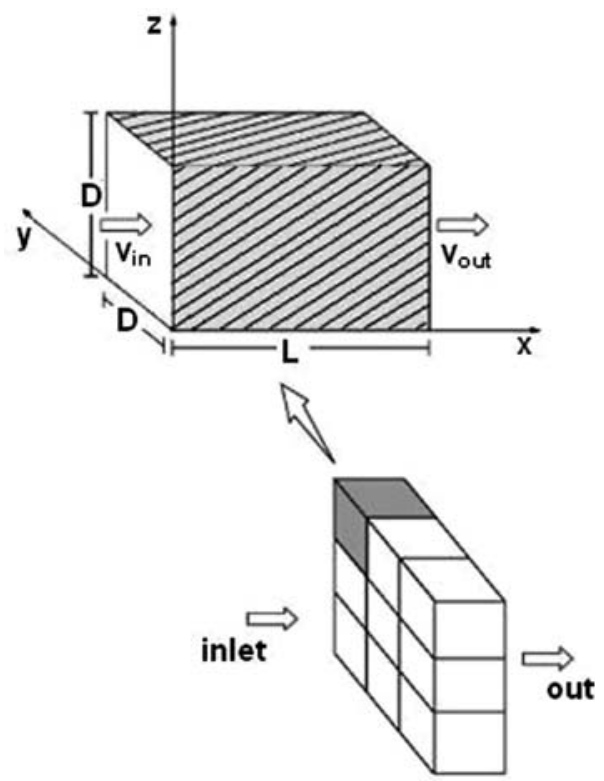

Fig. 1 Schematics of the modular reactor 
generation, and Fluent (v. 6.3.26, ANSYS, Inc., USA) for the numerical three-dimensional solving of the mathematical model, computer simulations were carried out.

In previous work, we showed that the solutions are independent of the grid and the step of time, and that the numerical methodology was validated through the proper adjustment of numerical results with experimental data.

Simulations were carried out by varying the ratio between the width and length $(D / L)$ of the reactor for certain velocities $\left(v_{\mathrm{in}}\right)$ and temperatures of the inlet air $\left(T_{\text {in }}\right)$, assuming a constant volume of the reactor $(V)$. For each simulation, the temperature profile of the reactor was calculated and maximum temperature recorded. The optimum geometry of the reactor was considered one where the maximum temperature was equal to $35^{\circ} \mathrm{C}$ without the use of any external cooling system. This temperature is considered optimum for growth of Aspergillus fungus (Mitchell et al. 2004b; Parra et al. 2004).

The simulations were carried out for air inlet velocity between 0.002 and $0.006 \mathrm{~m} \mathrm{~s}^{-1}$. This parameter is important to the process, since the inlet air provides oxygen to the system, but also affects the temperature and moisture of the bed. Very low velocities may result in insufficient oxygenation in the bed, and high velocities could compromise the production and/or stability of the desired metabolite. The range of velocity of the inlet air defined in this study was previously used successfully for the same type of substrate (Hasan et al. 1998; Martins et al. 2006).

\section{Results and discussion}

Figure 2 shows the profiles of temperature at various times of the bioprocess for a module of 0.521 , ratio $(D / L) 0.72$, velocity of the inlet air $\left(v_{\text {in }}\right) 0003 \mathrm{~m} \mathrm{~s}^{-1}$ and temperature of the inlet air $\left(T_{\text {in }}\right) 29.0^{\circ} \mathrm{C}$.

At the beginning of the bioprocess, as Fig. 2a shows, the temperature of the reactor is uniform, since the heat generation is low. That is because the microorganism is in the lag growth phase. Next, the organism enters the exponential phase of growth, which increases the heat generation. The temperature of the reactor increases as shown in Fig. $2 b, c$ presents a profile of temperature in which the peak temperature is observed. After that moment, the temperature of the reactor decreases, since the heat generation decreases due to the entrance of the microorganism in the stationary phase of growth and the admission of air cools the reactor, as shown in Fig. 2 d.

The influence of the velocity of the inlet air on the maximum temperature of the reactor is shown in Fig. 3. The maximum temperature of the reactor decreases, both

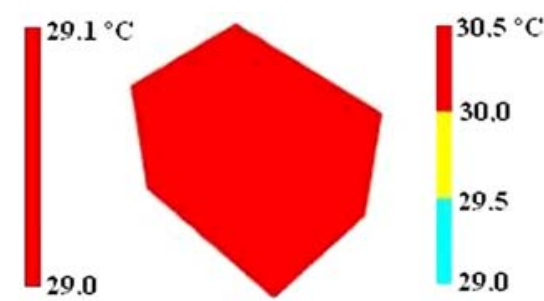

(a)
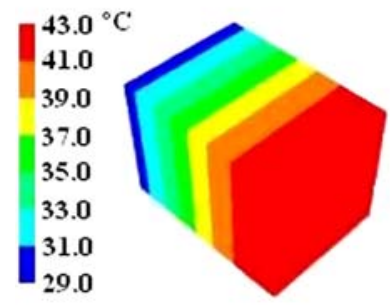

(c)

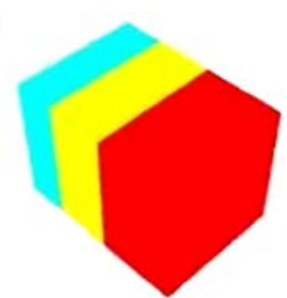

(b)
Fig. 2 Temperature profiles of a 0.521 module, $(D / L)=0.72$, $v_{\text {in }}=0.003 \mathrm{~m} \mathrm{~s}^{-1}$ and $T_{\text {in }}=29.0^{\circ} \mathrm{C}$ in $12 \mathrm{~h} \mathrm{(a),} 24 \mathrm{~h} \mathrm{(b),} 37 \mathrm{~h}(\mathbf{c})$, and $60 \mathrm{~h}(\mathbf{d})$ of bioprocess

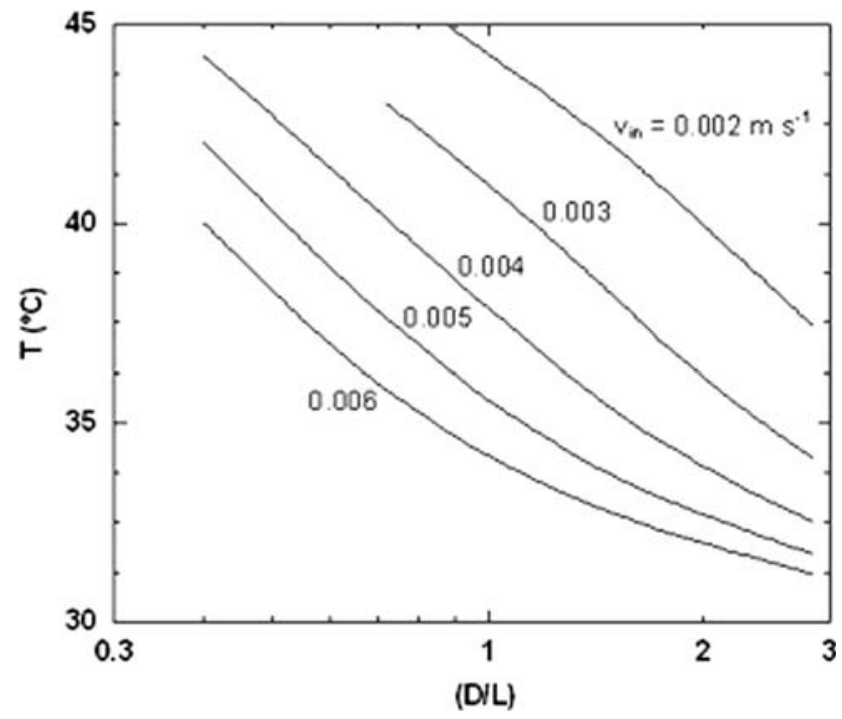

Fig. 3 Association between maximum reactor temperature and ratio $(D / L)$ for different air inlet velocities $\left(0.002 \leq v_{\text {in }} \leq 0.006 \mathrm{~m} \mathrm{~s}^{-1}\right.$, $\left.T_{\text {in }}=29.0^{\circ} \mathrm{C}\right)$

with the increase of the velocity the inlet air and with the increase in ratio between the width and length of the reactor $(D / L)$. The increase in these parameters causes the increase of flow of air and, consequently, the best cooling of the bed. Our research group found such behavior is also observed in a column bioreactor.

If the production process is suitable for small modules $(V=0.521)$, Fig. 3 makes it possible, from the air inlet velocity, to define which ratio $(D / L)$ should be used. 
Fig. 4 Optimum ratio $(D / L)$ according to different air inlet temperatures

$\left(28 \leq T_{\text {in }} \leq 31^{\circ} \mathrm{C}\right)$ and velocities

$\left(0.002 \leq v_{\text {in }} \leq 0.006 \mathrm{~m} \mathrm{~s}^{-1}\right)$ for a $0.521(\mathbf{a}), 1.01(\mathbf{b}), 1.51$ (c), $2.51(\mathbf{d}), 41(\mathbf{e})$, and $51(\mathbf{f})$ module

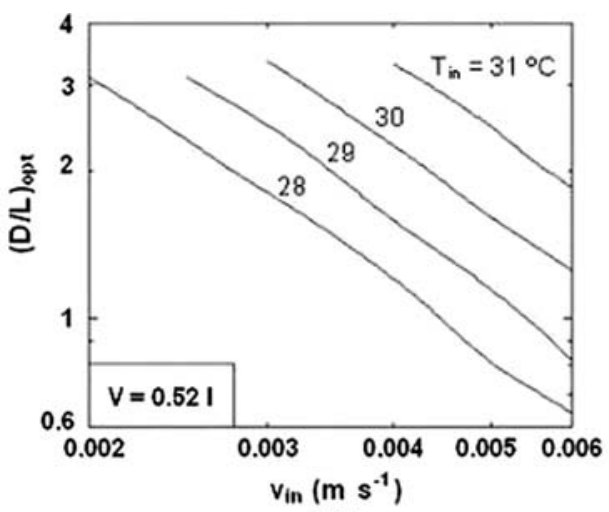

(a)

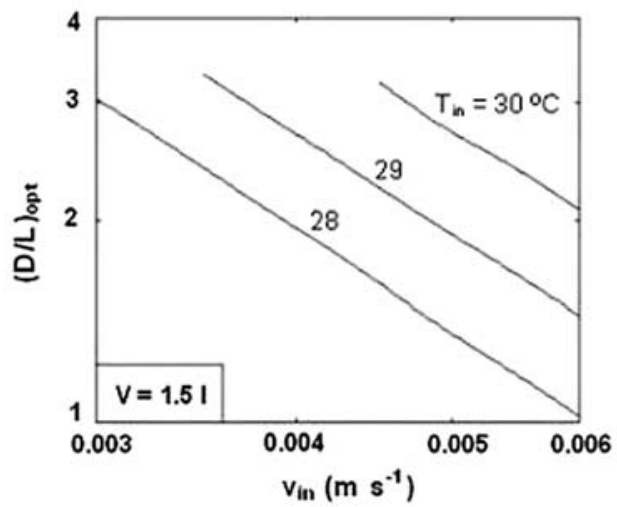

(c)

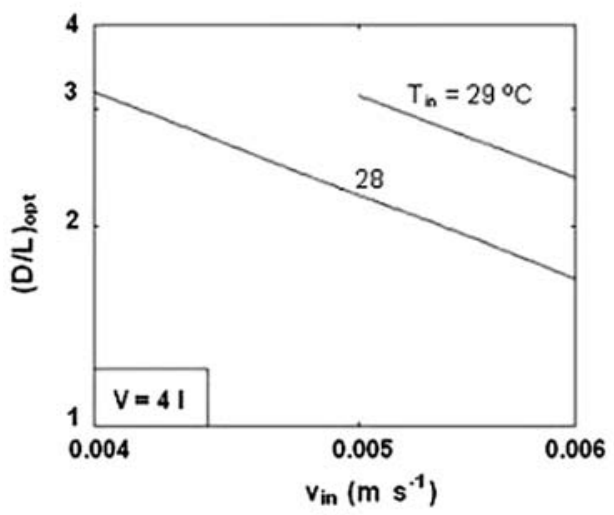

(e)

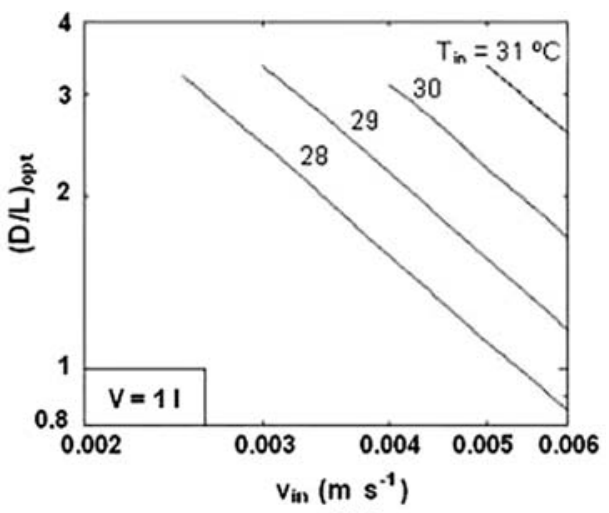

(b)

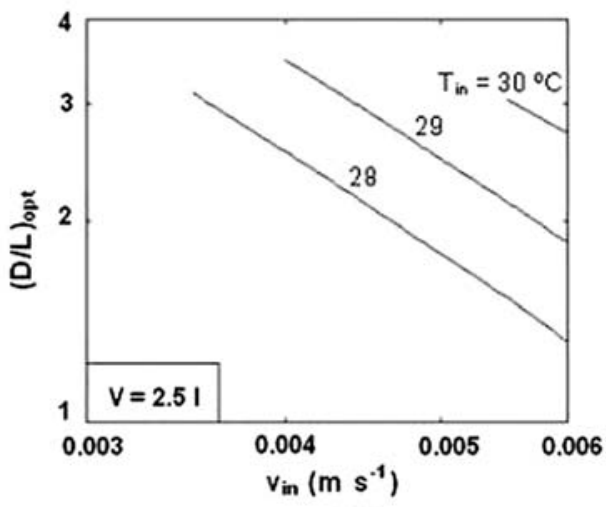

(d)

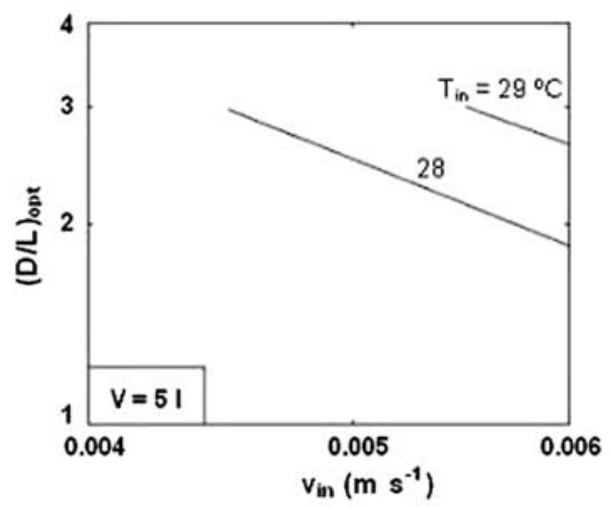

(f)
The optimal configuration $(D / L)_{\mathrm{opt}}$ of the bioreactor (at maximum temperature of $35^{\circ} \mathrm{C}$ ), is shown in Fig. 4, which depends on the velocity $\left(v_{\text {in }}\right)$ and temperature of the inlet air $\left(T_{\text {in }}\right)$. The geometric optimization is also presented for other reactors with different volumes in Fig. 4b-f.

Figure 4 shows the difficulty in scaling-up for the modular reactor for SSB. Smaller volumes allow the use of lower velocities of inlet air and lower ratios $(D / L)$, and consequently lower volumetric flow. Higher volumes, on the other hand, as well as demanding greater volumetric flow to maintain the temperature limit of $35^{\circ} \mathrm{C}$, also require lower temperatures of inlet air. There is a limit, however, for the use of low temperatures of inlet air, because low temperatures keep part of the reactor under the same condition, which is not favorable for the microorganism's development (Mitchell et al. 1999; Raghavarao et al. 2003).

The results shown in Fig. 4 allow the selection of an elementary module, with excellent geometry $\left[(D / L)_{\text {opt }}\right]$ depending on the parameters: inlet air temperature, air velocity, and volume of modules. Once the basic module has been selected, a combination of basic modules can be used to obtain the total volume of the reactor to be used. 
Figure $4 \mathrm{f}$ shows that the maximum possible volume of a hexahedral module without external cooling is 51 . The maximum acceptable air velocity inside the module $\left(v_{\max }=0.006 \mathrm{~m} \mathrm{~s}^{-1}\right)$ restricts the increase of scale. A higher velocity limit would allow the use of higher volumetric flow, which in turn would be able to cool larger bioreactors.

For the module of maximum volume (5 1) to operate under $35^{\circ} \mathrm{C}$ it needs an air flow with a velocity above $0.0045 \mathrm{~m} \mathrm{~s}^{-1}$ and maximum temperature of $29.0^{\circ} \mathrm{C}$.

\section{Conclusions}

This work has proposed a modular reactor for SSB, which has no external cooling system. The modules, with a hexahedral geometry and square section, are adaptable to different production scales and easy to assemble. The results show the optimum configuration of the reactor, $(D /$ $L)_{\text {opt }}$ as a function of the parameters of the inlet air temperature, air velocity and volume of modules. Once the basic module is selected, a combination of elementary modules can be used to obtain the total volume of the reactor to be employed.

The maximum volume of a hexahedral module without external cooling is 51 , which means an air flow velocity above $0.0045 \mathrm{~m} \mathrm{~s}^{-1}$ and temperature of $29.0^{\circ} \mathrm{C}$ or below are necessary.

\section{References}

Ashley VM, Mitchell DA, Howes T (1999) Evaluating strategies for overcoming overheating problems during solid-state fermentation in packed bed bioreactors. Biochem Eng J 3:141-150

Bejan A, Lorente S (2004) The constructal law and the thermodynamics of flow systems with configuration. Int $\mathrm{J}$ Heat Mass Transf 47:3203-3214

Couto SR, Sanromán MA (2006) Application of solid-state fermentation to food industry-a review. J Food Eng 76(3):291-302

Dalsenter FDH, Viccini G, Barga MC et al (2005) A mathematical model describing the effect of temperature variations on the kinetics of microbial growth in solid-state culture. Process Biochem 40:801-807

Fernández-Fernández M, Pérez-Correa JR (2007) Realistic model of a solid substrate fermentation packed-bed pilot bioreactor. Process Biochem 42:224-234

Hasan SDM, Costa JAV, Sanzo AVL (1998) Heat transfer simulation of solid state fermentation in packed-bed bioreactor. Biotechnol Tech 12:787-791
Lareo C, Sposito AF, Bossio AL et al (2006) Characterization of growth and sporulation of Mucor bacilliformis in solid state fermentation on an inert support. Enzyme Microb Technol 38:391-399

Leung P, Ishii K, Benson J (2005) Modularization of work tasks for global engineering. ASME international mechanical engineering congress and exposition, Orlando, EUA, ISBN 0-79183769

Maliska CR (2004) Transferência de Calor e Mecânica dos Fluidos Computacional. LTC, Rio de Janeiro

Martins VG, Kalil SJ, Bertolin TE et al (2006) Solid state biosurfactant production in a fixed-bed column bioreactor. $\mathrm{Z}$ Naturforsch C J Biosci 61(9-10):721-726

Mitchell DA, von Meien OF (2000) Mathematical modeling as a tool to investigate the design and operation of zymotis packed-bed bioreactor for solid-state fermentation. Biotechnol Bioeng 68(2):127-135

Mitchell DA, Pandey A, Sangsurasak P et al (1999) Scale-up strategies for packed-bed bioreactors for solid-state fermentation. Process Biochem 35:167-178

Mitchell DA, von Meien OF, Krieger N (2003) Recent developments in modeling of solid-state fermentation: heat and mass transfer in bioreactors. Biochem Eng J 13(2-3):137-147

Mitchell DA, von Meien OF, Krieger N et al (2004a) A review of recent developments in modeling of microbial growth kinetics and intraparticle phenomena in solid-state fermentation. Biochem Eng J 17:15-26

Mitchell D, Parra R, Aldred D et al (2004b) Water and temperature relations of growth and ochratoxin. A production by Aspergillus carbonarius strains from grapes in Europe and Israel. J Appl Microb 97:439-445

Parra R, Aldred D, Archer DB et al (2004) Water activity, solute and temperature modify growth and spore production of wild type and genetically engineered Aspergillus niger strains. Enzyme Microb Technol 35:232-237

Raghavarao KSMS, Ranganathan TV, Karanth NG (2003) Some engineering aspects of solid-state fermentation. Biochem Eng $\mathrm{J}$ 13:127-135

Rahardjo YSP, Tramper J, Rinzema A (2006) Modeling conversion and transport phenomena in solid-state fermentation: a review and perspectives. Biotechnol Adv 24:161-179

Sangsurasak P, Mitchell DA (1995a) The investigation of transient multidimensional heat transfer in solid state fermentation. Chem Eng J 60:199-204

Sangsurasak P, Mitchell DA (1995b) Incorporation of death kinetics into a 2-dimensional dynamic heat transfer model for solid state fermentation. J Chem Technol Biotechnol 64:253-260

Sangsurasak P, Mitchell DA (1998) Validation of a model describing two-dimensional heat transfer during solid-state fermentation in packed bed bioreactors. Biotechnol Bioeng 60(6):739-749

Saucedo-Castañeda G, Gutiérrez-Rojas M, Bacquet G et al (1990) Heat transfer simulation in solid substrate fermentation. Biotechnol Bioeng 35:802-808

Smits JP, van Sonsbeek HM, Tramper J et al (1999) Modelling fungal solid-state fermentation: the role of inactivation kinetics. Bioprocess Eng 20:391-404

Soccol CR, Vandenberghe LPS (2003) Overview of applied solidstate fermentation in Brazil. Biochem Eng J 13:205-218 